\title{
Reperfusion treatment delays amongst patients with painless ST segment elevation myocardial infarction
}

\author{
Pin Pin Pek, PgDip(Psych)*; En Yun Loy, MSc, MPH ${ }^{\ddagger}$; Win Wah, MBBS, MPH ${ }^{\S}$; Andrew Fu Wah Ho, MBBS \\ Huili Zheng, $\mathrm{MSc}^{\ddagger}$; Stephanie Man Chung Fook-Chong, $\mathrm{MSc}^{\dagger}$; Terrance Siang Jin Chua, MBBS, MMed ${ }^{* *}$; \\ Tian Hai Koh, MBBS, MMed**; Khuan Yew Chow, MB BCh(Ire), MMed(Public Health)**; Nan Liu, PhD* ${ }^{*+}$; \\ Marcus Eng Hock Ong, MBBS, $\mathrm{MPH}^{* \dagger}$
}

\section{ABSTRACT}

Objective: Early reperfusion therapy in the treatment of ST segment elevation myocardial infarction (STEMI) patients can improve outcomes. Silent myocardial infarction is associated with poor prognosis, but little is known about its effect on treatment delays. We aimed to characterize STEMI patients presenting without complaints of pain to the emergency departments (EDs) in Singapore.

Methods: Retrospective data were requested from the Singapore Myocardial Infarction Registry (SMIR), a national level registry in Singapore. Painless STEMI was defined as the absence of pain (chest, back, shoulder, jaw, and epigastric pain) during ED presentation. The primary outcome was door-to-balloon (D2B) time, defined as the earliest time a patient arrived in the ED to balloon inflation. Secondary outcomes were 1-month and 1-year mortality and occurrence of adverse events.

Results: From January 2010 to December 2012, the SMIR collected 6412 cases; $10.9 \%$ of patients presented without any pain. These patients were older (median age $=75 \mathrm{v}$. 58 years old), more likely to be females $(39.9 \%$ v. $16.1 \%)$, Chinese (74.9\% v. $62.7 \%)$, obese (median body mass index [BMI] $=24.5 \mathrm{v} .22 .1)$, and with history of hypertension $(71.1 \% \mathrm{v}$. $54.6 \%)$, diabetes mellitus $(48.6 \%$ v. $37.0 \%)$, and acute myocardial infarction $(20.0 \%$ v. $12.3 \%)$. They had a longer median D2B (80.5 v. 63 minutes, $p<0.001)$ and a higher occurrence of 30 -day $(38.4 \%$ v. $5.7 \%)$ and 1-year mortality rates $(47.3 \%$ v. $8.5 \%)$.

Conclusion: A small proportion of STEMI patients presented without any pain to the ED. They tended to have a higher D2B and risks of mortality. Targeted effort is required to improve diagnostic and treatment efficiency in this group.

\section{RÉSUMÉ}

Contexte: La reperfusion précoce dans le traitement de l'infarctus du myocarde avec sus-décalage du segment ST (STEMI) peut améliorer les résultats cliniques. L'infarctus du myocarde silencieux est associé à un sombre pronostic, mais on en connaît peu sur l'incidence qu'il a sur les retards de traitement. L'étude visait donc à caractériser les patients qui souffraient d'un STEMI, sans ressentir de douleur thoracique, et qui ont consulté dans un service des urgences (SU), à Singapour.

Méthode: II y a eu une collecte de données rétrospectives, tirées du Singapore Myocardial Infarction Registry (SMIR), un registre national établi à Singapour. Le STEMI indolore a été défini comme l'absence de douleur (à la poitrine, dans le dos, à l'épaule, à la mâchoire ou à l'épigastre) durant le séjour au SU. Le principal critère d'évaluation était le temps écoulé depuis la première minute d'arrivée au SU jusqu'au gonflement du ballonnet. Les critères d'évaluation secondaires consistaient en la mortalité au bout de 1 mois et de 1 an et en la survenue d'événements indésirables.

Résultats: De janvier 2010 à décembre 2012, 6412 cas ont été inscrits dans le SMIR; dans 10,9\% d'entre eux, les patients ne présentaient pas de douleur. En général, il s'agissait de personnes : âgées (âge médian : 75 ans contre [c.] 58 ans), de sexe féminin (39,9\% c. $16,1 \%)$, d'origine chinoise $(74,9 \%$ c. $62,7 \%$ ), obèses (IMC médian : 24,5 c. 22,1 ) et ayant des antécédents d'hypertension artérielle $(71,1 \%$ c. $54,6 \%)$, de diabète sucré $(48,6 \%$ c. $37,0 \%)$ ou d'infarctus aigu du myocarde (20,0\% c. $12,3 \%)$. Le temps médian écoulé depuis I'arrivée au SU jusqu'au gonflement du ballonnet était plus long $(80,5$ c. 63 minutes; $p<0,001)$ et le taux de mortalité au bout de 30 jours $(38,4 \%$ c. $5,7 \%)$ et de 1 an, plus élevé $(47,3 \%$ c. $8,5 \%)$ que chez les autres patients.

From the *Department of Emergency Medicine; †Division of Research, Singapore General Hospital, Singapore; $¥$ National Registry of Diseases Office, Health Promotion Board, Singapore; §Centre for Infectious Disease Epidemiology and Research, Saw Swee Hock School of Public Health, Tahir Foundation Building, National University of Singapore, Singapore; IEmergency Medicine Residency Program, SingHealth Services, Singapore; **Department of Cardiology, National Heart Centre, Singapore; and t†Centre for Quantitative Medicine, Duke-NUS Medical School, Singapore.

Correspondence to: Pin Pin Pek, Department of Emergency Medicine, Singapore General Hospital, Outram Road, Singapore 169608; Email: maeve_sgh@yahoo.com. 
Conclusion: Une faible proportion des patients atteints d'un STEMI et ayant consulté au SU ne présentaient pas de douleur. Le temps écoulé depuis l'arrivée au SU jusqu'au gonflement du ballonnet tendait à se prolonger, et le risque de mortalité, à s'accroître. Un effort ciblé s'impose donc pour améliorer l'efficience au regard du diagnostic et du traitement dans ce groupe particulier de malades.

Keywords: door-to-balloon, mortality, myocardial infarction, painless STEMI, registry

\section{INTRODUCTION}

Ischemic heart disease (IHD) was the leading cause of death globally in 2012, with an increasing trend over the past decade. In 2012 alone, IHD claimed 7.4 million deaths, accounting for $13.2 \%$ of global deaths. ${ }^{1}$ Large scale registries investigating acute myocardial infarction (AMI), such as the National Registry of Myocardial Infarction and the National Cardiovascular Data Registry in the United States, the Vienna ST segment elevation myocardial infarction (STEMI) network and the Belgian STEMI registry in Europe, have been established in recent years to improve patient outcomes from AMI. Similarly, in Singapore, the Singapore Myocardial Infarction Registry (SMIR) was established in 2007 to understand AMI trends. IHD is ranked third in the principal causes of death in Singapore, according to the Ministry of Health in $2013 .^{2}$ The average number of AMI episodes in Singapore between 2007 and 2013 was 7829 per year, of which approximately $30 \%$ were STEMI cases. ${ }^{3}$

Early reperfusion therapy in the treatment of STEMI patients can improve outcomes. To shorten the door to reperfusion time, measures such as prehospital electrocardiogram (ECG) transmission in the field to the emergency departments (EDs) were adopted nationwide in Singapore in 2008. Ambulance protocols indicate that ECGs are to be performed on patients presenting with chest pain, breathlessness, and diaphoresis. Other atypical symptoms that ambulance crews are to observe include jaw pain, shoulder pain, and so forth. However, there exists a subgroup of STEMI patients without complaints of any form of pain.

A search on PubMed shows a paucity of literature on painless STEMI. A study by Cho et al. of the Korea Acute Myocardial Infarction Registry data showed that painless STEMI was associated with higher rates of inhospital mortality and 1-year major adverse cardiac events. ${ }^{5}$ In a study conducted in the United States, Coronado et al. found that AMI patients who presented to the ED without pain had a lower rate of admission to the critical care unit than similar patients who presented with pain; a higher mortality rate was also seen in patients with painless acute ischemia. ${ }^{6}$ Silent myocardial infarction is associated with poor prognosis, but little is known about its effect on treatment delays. ${ }^{7}$

Hence, we aimed to characterize STEMI patients presenting to EDs in Singapore without complaints of pain, and examine its association with delays in treatment and mortality.

\section{MATERIALS AND METHODS}

\section{Setting}

Singapore is a highly urbanized city-state spanning over 718.3 square kilometers of land mass and with a population of 5.3 million. ${ }^{8}$ At the time of the study, there were six major public hospitals and seven private hospitals equipped with modern EDs. ${ }^{9}$ The National Registry of Diseases Act was enacted in Singapore in $2007,{ }^{10}$ and it mandates that all AMI cases from both the public and private hospitals (mandatory notification for only private hospitals started in 2012) are to be sent to the SMIR, under the National Registry of Diseases Office (NRDO). This includes AMI deaths that occur at home and are certified by a medical practitioner (although the numbers are small). ${ }^{11}$

\section{Study population}

De-identified data of all STEMI cases presenting to the public and private hospitals between January 2010 and December 2012 were requested from the SMIR and analysed. Patients who suffered out-of-hospital or inhospital cardiac arrest were transferred from an external facility, and those who developed STEMI only during hospital admission were excluded from the analysis. The rationale for the exclusion was that these patients would have different processes of care.

\section{Data collection}

The SMIR used several methods in their data collection process, namely abstraction from medical claims, 
inpatient hospital discharge summaries and physical case notes, cardiac markers laboratory results, death certificates, and necropsy information. Identification of STEMI cases by the registry coordinators was through the International Classification of Diseases 9th and 10th Revision Codes recorded by attending emergency physicians in the case records. Quality assurance measures include a logic check for dates and categorical data, and range check for numeric data. Illogical data and out of range values were flagged to the registry coordinators for verification.

The data were categorized into two groups: painless and painful STEMI. Painless STEMI was defined as the absence of complaints of pain in the chest, jaw, shoulder, epigastric, and back during the entire ED presentation. Painful STEMI was defined as complaint of pain in any of these locations.

\section{Outcomes}

The primary outcome was door-to-balloon time (D2B), defined as the earliest time that the patient arrived in the ED to balloon inflation. Secondary outcomes were 1-month and 1-year mortality rates and occurrence of adverse events such as cardiogenic shock, reinfarction, acute renal failure, heart failure, complete heart block, cerebrovascular accident, and left ventricular systolic dysfunction.

\section{Statistical analysis plan}

Data entry was performed using an electronic platform: the National Disease Registries System. Stata version 11 (StataCorp LP, College Station, Texas) was used for data analysis. Missing data were excluded from analysis.

Categorical variables were presented as frequency with percentage and chi-square tests used to determine whether their distributions differed by STEMI pain type $(p<0.05)$. Continuous variables were presented as a median with range, and the Mann-Whitney $U$ test was used to determine whether they differed by STEMI pain type $(p<0.05)$.

Multivariate logistic regression analysis was used to identify independent predictors of $\mathrm{D} 2 \mathrm{~B}>60$ minutes; odds ratios with $95 \%$ confidence intervals are presented. We used 60 minutes as the cut-off, because both the Global Use of Strategies to Open Occluded Arteries in Acute Coronary Syndromes (GUSTO-IIb) ${ }^{12}$ and $\mathrm{NRMI}^{13}$ trials have shown that the lowest mortality rates were achieved when percutaneous coronary intervention (PCI) was performed within 60 minutes of presentation at the ED. Survival outcomes (1 month and 1 year from admission date) were estimated using a Kaplan-Meier survival analysis; a log-rank test was used to test the survival difference between the painless group and the group with pain. Statistical significance was set at $p<0.05$. For the Kaplan-Meier survival analysis, the survival time for those who died within 1 month and 1 year was defined as the days from the date of ED admission to the date of death. A Cox proportional hazards regression analysis was used to determine the hazard ratio of painless STEMI on 1-month and 1-year mortality rates. The confounders included in the model were based on both statistical and clinical significance. Survival time was censored at 30 days and 365 days if there was no mortality during the 1-month and 1-year follow-up for both the Kaplan-Meier survival and Cox proportional hazards regression analyses.

\section{Ethics approval}

The Central Institutional Review Board granted approval for this research project with a waiver of patient consent, as the data used in this study were de-identified registry data.

\section{RESULTS}

Figure 1 shows the patient flow diagram. A total of 6412 STEMI patients were enrolled by the SMIR between January 2010 and December 2012. Patients totalling 1745 were excluded from analysis; 383 were transfer cases, 756 were inpatient STEMI cases, and 797 were cardiac arrest cases, leaving 4667 cases eligible for analysis.

STEMI patients totalling 4158 presented with pain, and 509 patients presented without any pain to the EDs. Table 1 shows patients' baseline characteristics. Painless STEMI patients were older (median age $=75$ v. 58 years old, $p<0.001$ ), more likely to be female (39.9\% v. $16.1 \%, p<0.001)$, and of Chinese ethnicity $(74.9 \%$ v. $62.7 \%)$. They also tended to have higher rates of past medical history of diseases such as hypertension $(71.1 \%$ v. $54.6 \%, p<0.001)$, diabetes mellitus (48.6\% v. $37.0 \%, p<0.001)$, and AMI $(20.0 \%$ v. $12.3 \%$, $p<0.001$ ), but lower rates of history of dyslipidemia $(55.3 \%$ v. $62.6 \%, p<0.01)$ and PCI $(6.1 \%$ v. $9.9 \%$, $p<0.01)$. The majority of painless STEMI patients 


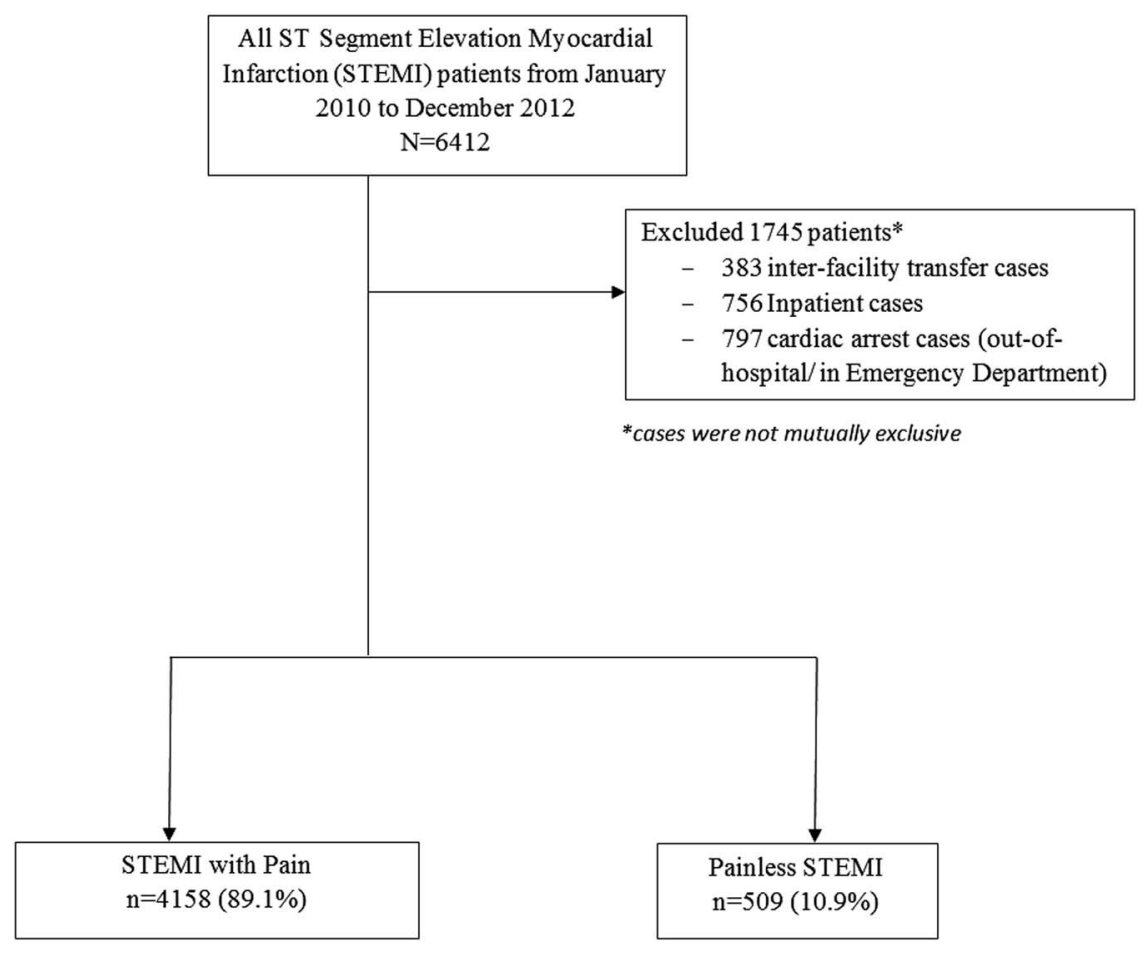

Figure 1. Patient flow diagram.

had never smoked before $(60.7 \%$ v. $37.5 \%, p<0.001)$ and also had a higher body mass index (BMI) than the painful STEMI patients $(24.5$ v. $22.1, p<0.001)$. Painless STEMI patients were more likely to present with syncope $(6.7 \%$ v. $1.9 \%, p<0.001)$ than diaphoresis $(19.8 \%$ v. $68.8 \%, p<0.001)$ compared to the group with pain. Painless STEMI patients were more likely to present with heart failure (Killip class 2 to 4), compared to painful STEMI patients.

Table 2 shows the process-of-care timings and patient outcomes. Painless STEMI patients had longer D2B time (80.5 v. 63 minutes, $p<0.001)$. In terms of adverse outcomes, painless STEMI patients were more likely to suffer cardiogenic shock $(11.8 \%$ v. $4.1 \%$, $p<0.001)$, heart failure $(22.4 \%$ v. $10.1 \%, p<0.001)$, complete heart block $(4.9 \%$ v. $3.3 \%, p<0.05)$, acute renal failure $(14.9 \%$ v. $4.8 \%, p<0.001)$, and death within 30 days $(38.4 \%$ v. $5.7 \%, p<0.001)$ and 1 year from admission $(47.3 \%$ v. $8.5 \%, p<0.001)$. The group with pain was more likely to have left ventricular systolic dysfunction $(69.8 \%$ v. $62.3 \%, p<0.001)$ as an adverse outcome. Using the Kaplan-Meier survival analysis and log-rank test, we found that survival outcomes were significantly poorer in the painless group
(68.5\%, 95\% CI $64.2-72.4, p<0.001)$ than the group with pain at 1 month $(96.1 \%, 95 \%$ CI 95.5 - 96.6, $p<0.001)$ and similarly at 1 year from admission (54.8\%, 95\% CI $50.3-59.0, p<0.001$ v. $92.4 \%$, 95\% CI 91.6 - 93.2, $p<0.001$ ) (Figure 2). In a multivariate Cox proportional hazards regression analysis, age, race (Indian and Malay), past medical history of diabetes mellitus and AMI, smoker, ex-smoker, Killip class 2 to 4 , and painless presentation were significantly associated with a higher risk of mortality outcomes at 1 month and 1 year. Painless STEMI patients were 2.9 and 2.5 times more likely than the group with pain to die from any cause during the 1-month (HR 2.85, 95\% CI 2.21 - 3.68) and 1-year follow-up (adjusted HR 2.46, 95\% CI $2.03-2.99$ ).

Table 3 shows the multivariate model for independent predictors of D2B $>60$ minutes. After multivariate analysis, painless presentation of STEMI remained an independent predictor for D2B >60 minutes (OR 1.89, $95 \%$ CI 1.12 - 3.20, $p=0.02)$. In addition, other independent predictors identified were female gender, past medical history of coronary artery bypass grafting surgery, private transport utilization, after-office-hours presentation, and Killip classes 3 and 4. 
Table 1. Baseline characteristics of patients

\begin{tabular}{|c|c|c|c|}
\hline & $\begin{array}{l}\text { STEMI with Pain } \\
\qquad(\mathrm{N}=4158)\end{array}$ & $\begin{array}{l}\text { Painless STEMI } \\
\qquad(\mathrm{N}=509)\end{array}$ & $p$-value \\
\hline Age, median (range), years & $58(21-102)$ & $75(21-100)$ & $<0.001^{*}$ \\
\hline \multicolumn{4}{|l|}{ Gender, $n(\%)$} \\
\hline Male & 3488 (83.9) & $306(60.1)$ & $<0.001^{*}$ \\
\hline \multicolumn{4}{|l|}{ Race, $n(\%)$} \\
\hline Chinese & $2606(62.7)$ & 381 (74.9) & $<0.001^{*}$ \\
\hline Malay & $866(20.8)$ & $87(17.1)$ & \\
\hline Indian & $623(15.0)$ & $36(7.1)$ & \\
\hline Others & $63(1.5)$ & $5(1.0)$ & \\
\hline \multicolumn{4}{|l|}{ Past medical history, $n$ (\%) } \\
\hline Hypertension & $2265(54.6)$ & $360(71.1)$ & $<0.001^{*}$ \\
\hline Diabetes mellitus & $1536(37.0)$ & $246(48.6)$ & $<0.001^{*}$ \\
\hline Dyslipidemia & $2600(62.6)$ & $280(55.3)$ & $0.010^{*}$ \\
\hline Acute myocardial infarction & 509 (12.3) & $101(20.0)$ & $<0.001^{*}$ \\
\hline Coronary artery bypass grafting & $61(1.5)$ & $6(1.2)$ & 0.616 \\
\hline $\begin{array}{l}\text { Percutaneous transluminal coronary } \\
\text { angioplasty/Percutaneous coronary intervention }\end{array}$ & 411 (9.9) & $31(6.1)$ & $0.006^{*}$ \\
\hline Smoking status, $n(\%)$ & & & $<0.001^{*}$ \\
\hline Current & $2207(53.5)$ & $112(23.2)$ & \\
\hline Ex-smoker & $572(13.9)$ & $78(16.1)$ & \\
\hline Never & 1549 (37.5) & $293(60.7)$ & \\
\hline Body mass index, median(range) & $22.1(12.3-43.4)$ & $24.5(12.6-47.1)$ & $<0.001^{*}$ \\
\hline \multicolumn{4}{|l|}{ Presenting symptoms, $n$ (\%) } \\
\hline Breathlessness & $2480(59.6)$ & $288(56.6)$ & $0.184^{*}$ \\
\hline Diaphoresis & $2862(68.8)$ & $101(19.8)$ & $<0.001^{*}$ \\
\hline Syncope & $79(1.9)$ & $34(6.7)$ & $<0.001^{*}$ \\
\hline After-office hours presentation, $n(\%)^{\dagger}$ & $2537(61.0)$ & $299(58.7)$ & 0.322 \\
\hline Killip score at admission, $n(\%)$ & & & $<0.001^{*}$ \\
\hline Class 1 & $3495(84.1)$ & $310(60.9)$ & \\
\hline Class 2 & $278(6.7)$ & $70(13.8)$ & \\
\hline Class 3 & $177(4.3)$ & 69 (13.6) & \\
\hline Class 4 & $208(5.0)$ & $60(11.8)$ & \\
\hline \multicolumn{4}{|l|}{ Troponin $T$} \\
\hline Median of the mean of first 2 or 3 readings (maximum of 5) & $2.31(0.003-67.9)$ & $0.94(0.006-22.7)$ & $<0.001^{*}$ \\
\hline Median of the peak of first 2 or 3 readings (maximum of 5) & $3.74(0.003-87.1)$ & $1.2(0.006-90.0)$ & $<0.001^{*}$ \\
\hline \multicolumn{4}{|l|}{$C K$} \\
\hline Median of the mean of first 2 or 3 readings (maximum of 5) & $1072.4(26.7-13934)$ & $319.4(13.7-12895.8)$ & $<0.001^{*}$ \\
\hline Median of the peak of first 2 or 3 readings (maximum of 5) & $783(27-13650)$ & $338(15-9768)$ & $<0.001^{*}$ \\
\hline \multicolumn{4}{|l|}{$C K-M B$} \\
\hline Median of the mean of first 2 or 3 readings (maximum of 5) & $70(0.7-1000)$ & $12.5(1-433.7)$ & $<0.001^{*}$ \\
\hline Median of the peak of first 2 or 3 readings (maximum of 5) & $57.3(0.8-1000)$ & $9.2(1-854)$ & $<0.001^{*}$ \\
\hline Creatinine, median (range) & $87(12-1348)$ & $113(24-1537)$ & $<0.001^{*}$ \\
\hline Hemoglobin, median (range) & $14.5(4.5-20.0)$ & $12.8(5.3-19.1)$ & $<0.001^{*}$ \\
\hline \multicolumn{4}{|l|}{ Electrocardiogram diagnosis, $n(\%)$} \\
\hline Anterior & $2144(51.6)$ & $305(59.9)$ & $<0.001^{*}$ \\
\hline Posterior & $523(12.6)$ & $43(8.5)$ & $<0.001^{*}$ \\
\hline Inferior & $1888(45.4)$ & $175(34.4)$ & $<0.001^{*}$ \\
\hline Lateral & $1456(35.0)$ & $205(40.3)$ & $0.019 *$ \\
\hline Left bundle branch block & $10(0.24)$ & $5(0.98)$ & $0.005^{*}$ \\
\hline Right ventricular & $233(5.6)$ & $22(4.3)$ & 0.230 \\
\hline
\end{tabular}




\begin{tabular}{|c|c|c|c|}
\hline & $\begin{array}{l}\text { STEMI with Pain } \\
\qquad(\mathrm{N}=4158)\end{array}$ & $\begin{array}{l}\text { Painless STEMI } \\
\qquad(\mathrm{N}=509)\end{array}$ & $p$-value \\
\hline \multicolumn{4}{|c|}{ Process-of-care-timings, median (range), minutes } \\
\hline Door-to-balloon & $63(9-1641)$ & $80.5(34-207)$ & $<0.001^{*}$ \\
\hline Symptom-to-door & $149(0-10556)$ & $86(10-1692)$ & $<0.001^{*}$ \\
\hline Symptom-to-balloon & $205(43-4643)$ & $182.5(78-1579)$ & 0.292 \\
\hline \multicolumn{4}{|l|}{ Treatment, $n$ (\%) } \\
\hline Primary PTCA/PCI & 3127 (99.6) & $109(98.2)$ & $<0.001^{*}$ \\
\hline Coronary artery bypass grafting & $5(0.16)$ & 0 & 0.434 \\
\hline Complications, $n(\%)$ & $N=3472$ & $N=451$ & \\
\hline Cardiogenic shock & $144(4.1)$ & $53(11.8)$ & $<0.001^{*}$ \\
\hline Heart failure & $350(10.1)$ & $101(22.4)$ & $<0.001^{*}$ \\
\hline Reinfarction & $14(0.40)$ & $2(0.44)$ & 0.995 \\
\hline Complete heart block & 114 (3.3) & $22(4.9)$ & $0.043^{*}$ \\
\hline Acute renal failure & $165(4.8)$ & $67(14.9)$ & $<0.001^{*}$ \\
\hline Cerebrovascular accident & $38(1.1)$ & $8(1.8)$ & 0.153 \\
\hline Left ventricular systolic dysfunction & $2423(69.8)$ & $281(62.3)$ & $<0.001^{*}$ \\
\hline Death (30 days from date of admission) & $199(5.7)$ & $173(38.4)$ & $<0.001^{*}$ \\
\hline Death (1 year from date of admission) & $352(8.5)$ & 241 (47.3) & $<0.001^{*}$ \\
\hline
\end{tabular}

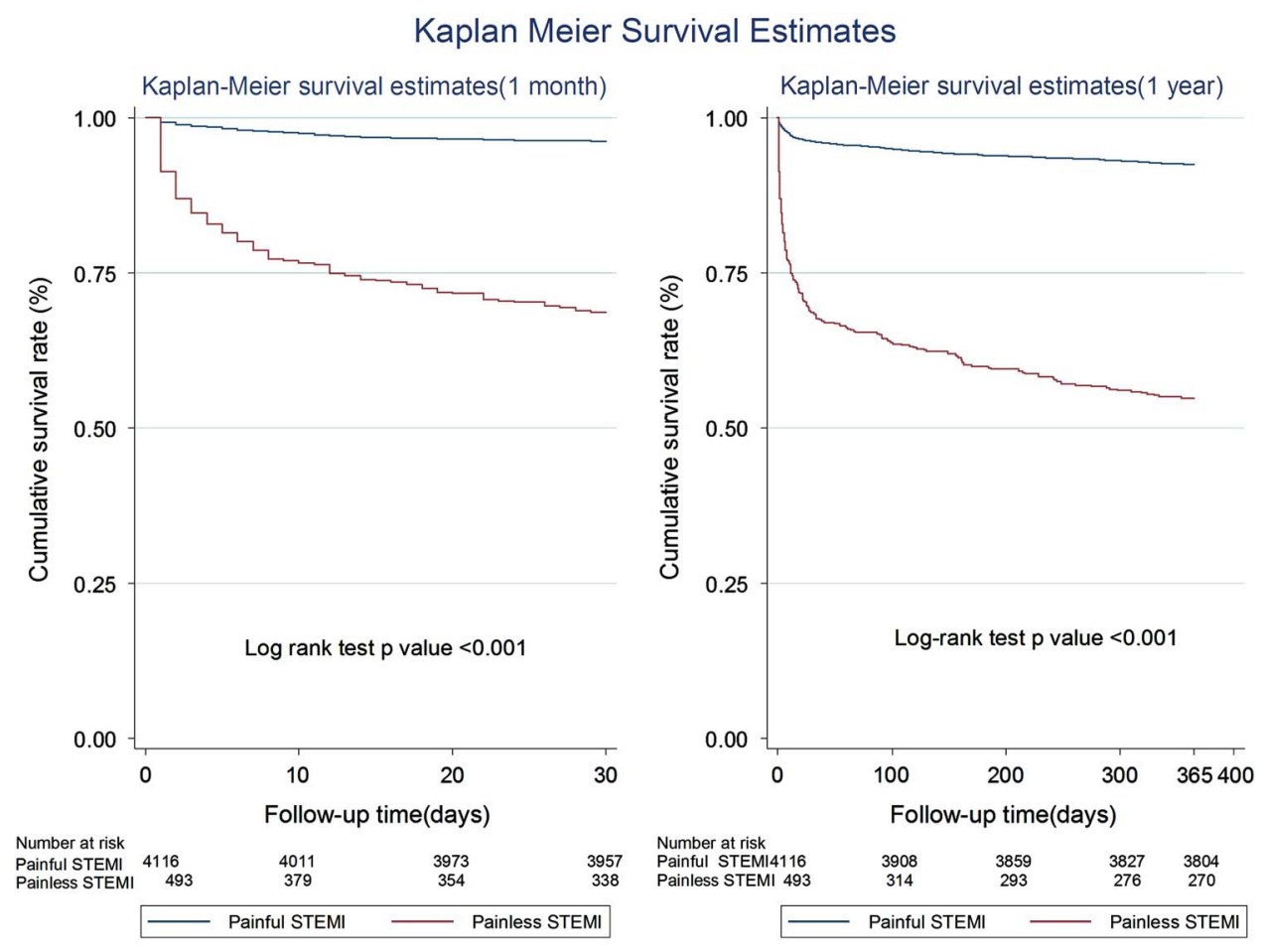

Figure 2. Kaplan-Meier survival analysis at 1 year from date of admission. STEMI = ST segment elevation myocardial infarction.

\section{DISCUSSION}

The present study shows that about $11 \%$ of STEMI patients who presented to the ED had no complaints of pain and that painless STEMI patients had different clinical profiles from the group with pain. This group of patients tended to be sicker upon presentation at the ED (higher Killip score) and was also more likely to 


\begin{tabular}{|c|c|c|c|}
\hline $\mathrm{D} 2 \mathrm{~B}>60$ minutes & Odds ratio & 95\% Confidence interval & $p$-value \\
\hline Age & 1.01 & $1.00-1.01$ & 0.06 \\
\hline Female & 1.89 & $1.48-2.43$ & $<0.001^{*}$ \\
\hline History of coronary artery bypass grafting (CABG) & 5.82 & $2.20-15.40$ & $<0.001^{*}$ \\
\hline History of percutaneous coronary intervention (PCI) & 1.03 & $0.73-1.46$ & 0.87 \\
\hline History of acute myocardial infarction (AMI) & 1.08 & $0.77-1.51$ & 0.66 \\
\hline Painless STEMI & 1.89 & $1.12-3.20$ & $0.02^{*}$ \\
\hline Private transport & 2.15 & $1.85-2.51$ & $<0.001^{*}$ \\
\hline After office hours presentation & 2.19 & $1.87-2.55$ & $<0.001^{*}$ \\
\hline \multicolumn{4}{|l|}{ Killip class at admission } \\
\hline 2 & 1.33 & $0.91-1.94$ & 0.15 \\
\hline 3 & 3.64 & $2.01-6.62$ & $<0.001^{*}$ \\
\hline 4 & 1.69 & $1.21-2.36$ & $0.002 *$ \\
\hline
\end{tabular}

suffer poorer outcomes. Painless STEMI was associated with longer D2B time even after adjusting for other predictors of reperfusion delay in the multivariate analysis. From the study, we observed that the mortality rates at 1 month and 1 year for painless STEMI patients were extremely high, at almost $40 \%$ and $50 \%$, respectively, that is, 4-5 out of every 10 painless STEMI patients will die. Compared to the group with pain, painless STEMI patients were 2.9 and 2.5 times more likely to experience 1-month and 1-year mortality rates.

Our study mirrors the findings of the Korea Acute Myocardial Infarction Registry study. ${ }^{5}$ Cho et al. similarly found that $11 \%$ of the STEMI patients in their study presented without pain to the hospitals. In congruence to our study, Cho et al. observed that painless STEMI patients were older, more likely to be females, and had higher rates of history of diabetes but lower rates of dyslipidemia. Their study also showed that painless STEMI patients had longer D2B times, were less likely to be offered PCI, and had higher mortality rates (in-hospital and at 1-year post admission).

Previous studies have shown that a longer D2B time was associated with increased mortality and morbidity. ${ }^{14-16}$ Hence, a longer D2B time seen in the painless STEMI group (painless group had a D2B of 80.5 minutes, whereas the group with pain had a D2B of 63 minutes) could be one of the contributing factors to their poorer outcomes. A longer D2B time is likely due to a delay in acquiring ECGs, mis-triaging (lower triage priority), and so forth, because of the lack of painful symptoms in this group of patients. The most common presenting symptom amongst painless STEMI patients was breathlessness $(56.6 \%)$, followed by diaphoresis (19.8\%) and syncope $(6.7 \%)$.

Recent studies have suggested that symptom-to-door (S2D) and symptom-to-balloon (S2B) times are better indicators of outcomes in STEMI patients. ${ }^{17-19}$ However, for the painless group, S2D and S2B times may not be the best indicators of outcomes. As we noted in our study that, although the S2D and S2B times of the painless STEMI group were shorter as compared to the group with pain, outcomes were poorer. We postulated, however, that ischemia might be more likely to have begun in the painless group before the development of any symptoms. One indicator of long ischemia time in the painless group is that a larger proportion of these patients presented with higher Killip classes at the EDs (see Table 1). Hence, poorer outcomes of this group of patients could possibly be explained by their longer total ischemic time.

\section{STRENGTHS AND LIMITATIONS}

The strength of this study was the usage of the national registry data, which represented all AMI cases reported from both public and private hospitals in Singapore. One of the limitations of a registry study is that the associations observed are not causative, that is, treatment delays and poorer outcomes may be due to other confounders apart from painless presentation. We found, however, in the multivariate analysis, that painless presentation independently predicted longer D2B time and 1-month and 1-year mortality rates. 
We also note that the distribution of sample size between the painless group and the group with pain was not equal, with the sample ratio at approximately 1:8. However, this study is a population-based one rather than a sample-based study and thus gives a true reflection of the STEMI population in Singapore. Moreover, there was minimal selection-bias because the patients in each group were categorized according to their presenting symptoms; presenting symptoms were extracted by registry coordinators who were independent from the study. Future studies, however, could explore a study design involving matched controls to circumvent this issue.

Cho et al..$^{5}$ posited that the higher frequency of the presence of $\mathrm{Q}$ waves on the ECGs of painless STEMI patients in their study was indicative of the longer ischemia time of this group of patients. However, in our study, we did not collect detailed ECG readings and thus are not able to offer additional support for our conjecture that the painless STEMI patients in our study had longer ischemia time.

Additionally, we did not collect other pertinent information such as triage priority and other processes of care timings (e.g., time ECG was acquired) in our study. Such information would help elucidate the reasons for treatment delays in the painless STEMI group.

\section{FUTURE PLANS}

Triage nurses and clinicians could be made aware of the profile of this subgroup of patients and instructed to order timely ECG for patients who present with diaphoresis, breathlessness, and syncope, despite the absence of pain complaints. Public educational efforts are also needed to educate the public to seek early treatment when they encounter such symptoms and especially so if they have a past medical history of diseases such as diabetes, hypertension, and AMI. Future studies can also collect and analyse information such as processes of care timings, detailed ECG recordings, and so forth, of painless STEMI patients to further elucidate the cause of treatment delays and poorer outcomes in this group of patients. This will help in developing plans for improvement of patient care for these patients.

\section{CONCLUSIONS}

A small proportion of STEMI patients presented without any pain to the ED. They tended to have higher D2B times and higher risks of mortality.
Targeted effort is required to improve diagnostic and treatment efficiency in this group.

Competing interests: None declared.

\section{REFERENCES}

1. World Health Organization (WHO). The top 10 causes of death; 2014. Available at: http://www.who.int/mediacentre/ factsheets/fs310/en/ (accessed 30 June 2015).

2. Ministry of Health. Principal causes of death. Available at: https://www.moh.gov.sg/content/moh_web/home/statistics/ Health_Facts_Singapore/Principal_Causes_of_Death.html (accessed 30 June 2015).

3. National Registry of Diseases Office. Acute myocardial infarction (AMI); 2015. Available at: https://www.nrdo.gov. $\mathrm{sg} /$ publications/ami (accessed 30 June 2015).

4. Ong MEH, Wong ASL, Seet CM, et al. Nationwide improvement of door-to-balloon times in patients with acute ST-segment elevation myocardial infarction requiring primary percutaneous coronary intervention with out-ofhospital 12-lead ECG recording and transmission. Ann Emerg Med 2013;61(3):339-47.

5. Cho JY, Jeong MH, Ahn YK, et al. Comparison of outcomes of patients with painless versus painful ST-segment elevation myocardial infarction undergoing percutaneous coronary intervention. Am 7 Cardiol 2012;109(3):337-43.

6. Coronado BE, Pope JH, Griffith JL, et al. Clinical features, triage, and outcome of patients presenting to the ED with suspected acute coronary syndromes but without pain: a multicenter study. Am $\mathscr{f}$ Emerg Med 2004;22(7):568-74.

7. Raby KE, Goldman L, Cook EF, et al. Long-term prognosis of myocardial ischemia detected by Holter monitoring in peripheral vascular disease. Am 7 Cardiol 1990;66(19):1309-13.

8. Statistics Singapore. Latest data. Available at: http://www. singstat.gov.sg/statistics/latest-data\#14 (accessed 1 July 2015).

9. Wen LS, Venkataraman A, Sullivan AF, et al. National inventory of emergency departments in Singapore. Int 7 Emerg Med 2012;5(1):38.

10. Singapore Statutes Online, 201B. National Registry of Diseases Act. Available at: http://statutes.agc.gov.sg (accessed 1 July 2015).

11. Singapore Myocardial Infarction Registry, National Registry of Diseases Office, Ministry of Health Singapore. Trends in acute myocardial infarction in Singapore, 2007-2013; 2015. Available at: https://www.nrdo.gov.sg/publications/ami (accessed 1 August 2015).

12. Berger PB, Ellis SG, Holmes DR, et al. Relationship between delay in performing direct coronary angioplasty and early clinical outcome in patients with acute myocardial infarction: results from the Global Use of Strategies to Open Occluded Arteries in Acute Coronary Syndromes (GUSTO-IIb) trial. Circulation 1999;100(1):14-20.

13. Cannon CP, Gibson CM, Lambrew CT, et al. Relationship of symptom-onset-to-balloon time and door-to-balloon time with mortality in patients undergoing angioplasty for acute myocardial infarction. FAMA 2000;283(22): 2941-7. 
14. McNamara RL, Wang Y, Herrin J, et al. Effect of door-toballoon time on mortality in patients with ST-segment elevation myocardial infarction. I Am Coll Cardiol 2006; 47(11):2180-6.

15. Rathore SS, Curtis JP, Chen J, et al. Association of door-toballoon time and mortality in patients admitted to hospital with ST elevation myocardial infarction: national cohort study. BMF 2009;338:b1807.

16. Brennan AL, Andrianopoulos N, Duffy SJ, et al. Trends in door-to-balloon time and outcomes following primary percutaneous coronary intervention for ST-elevation myocardial infarction: an Australian perspective. Intern Med $\mathcal{J}$ 2014;44(5):471-7.
17. De Luca G, Suryapranata H, Zijlstra F, et al. Symptomonset-to-balloon time and mortality in patients with acute myocardial infarction treated by primary angioplasty. $7 \mathrm{Am}$ Coll Cardiol 2003;42(6):991-7.

18. Shiomi H, Nakagawa Y, Morimoto T, et al. Association of onset to balloon and door to balloon time with long term clinical outcome in patients with ST elevation acute myocardial infarction having primary percutaneous coronary intervention: observational study. BM7 2012;344:e3257.

19. Afilalo J, Piazza N, Tremblay S, et al. Symptom-to-door time in ST segment elevation myocardial infarction: overemphasized or overlooked? Results from the AMI-McGill study. Can 7 Cardiol 2008;24(3):213-6. 